\title{
Analysis of Behavioural Patterns of the Amazonian Manatee, Trichechus manatus manatus, under Human Care (Mammalia:Sirenia)
}

\author{
Kappel Isabelle*, Gansloßer Udo \\ Friedrich-Schiller-Universität Jena, Institut für Zoologie und Evolutions for schung, Germany.
}

*Corresponding Author: Isabelle Kappel, Friedrich-Schiller-Universität Jena, Institut für Zoologie und Evolutions for schung, Germany.

\begin{abstract}
Based on behavioural observations on the manatee group in the Zoo of Nuremberg the study analyzed conditions of husbandry regarding space and structure of the newly constructed tank. We also investigated the presence of possible stressors affecting the animals' behaviour by recording their breathing frequencies. We collected 1126 scan samples per individual and measured in total 620 samples of diving phases. We observed patterns of special preferences in space use depending on the individual and the time of day, corresponding to the behaviour in the wild. Besides that, we found significant differences in the length of diving phases within the group, which refer to the relationship between total body mass and breathing frequency range. Overall breathing frequencies didn't increase over the period of observation. This indicates a low stress level, according to similar studies on bottlenose dolphins, which have shown correlations between the increase of breathing frequencies and stress. The animals conditions, which we analysed were behaviourally appropriate for the manatees. The results of the study could contribute to the guidelines for keeping Amazonian manatees in the future.
\end{abstract}

\section{INTRODUCTION}

Knowledge of behavioural ecology and habitat use of Sirenians is critical for keeping them in zoos and for their conservation and population management in the wild. But data on habitat use and activity budgets are rare. How do they use their habitat during day and night time? Do they have specific preferences for open water or shallow water? Do they prefer diversity in environment? How do they react to external stressors like noises? Do they have specific patterns to surface and breathe depending on the environment? We do not know much about the stress management of this species. Time spend at the surface can relate to their availability for potential threats like hunters or boats in the wild and may also influence their behaviour under human care to avoid potential stressors like public noises or shadowing on the water surface (Marsh 2012). As noise travels fast through water, it might have been a great influence on marine mammals and their communication system. If we take a look at the data of Cetaceans (as well as for other marine mammals), it appears that they will suffer more from exposure to noise than other species, including rats and humans - both species for which there is some information available about the consequences of noise exposure. Cetaceans, for example, may have developed various strategies to deal with natural noise (i.e. the drowning out of a signal of interest by noise; Wright 2007). But what about the adaptive mechanisms of Sirenians? And are those mechanisms sufficientto compensate for the comparatively recent occurrence of anthropogenic noise in a zoo?

In order to understand how Sirenians use their environment and react to stress, we conducted this study on the manatee group of Nuremberg Zoo. The group consist of four individuals. The major aim of the study was to contribute to EAZA husbandry guidelines for manatees as the Zoo of Nuremberg keeps the EAZA studbook for the European population of Antillean Manatees.

We concentrated on the space-time-structure of the animals, which had been moved to a new tank system, less than three months before. Therefore, the study focused on the following questions: Is space use activity different depending on the individual and the time of day? Do the individuals show different lengths in breathing frequencies? Is there any increase that refers to potential stressors in the environment? 


\section{METHODS}

\subsection{Study Animals}

Table 1 and 2 describe the Nuremberg manatee group and the studbook data of the animals during the times of observation

Table1. Studbook data of the manatee group in Nuremberg Zoo (von Fersen 2012)

\begin{tabular}{|c|c|c|c|c|c|}
\hline Name & Sex & Birth Origin & Event & Location & $\begin{array}{c}\text { Birth/ Transfer } \\
\text { Date }\end{array}$ \\
\hline MARA & Female & Captiveborn & Birth & Nuremberg & $1994 / 02$ \\
\hline ZORRO & Male & Captiveborn & Birth & Odense & $2003 / 09$ \\
\cline { 4 - 6 } & & & Loanto & Nuremberg & $2009 / 12$ \\
\hline HERBERT & Male & Captiveborn & Birth & Nuremberg & $2009 / 01$ \\
\hline LUNA & Female & Captiveborn & Birth & Beauval & $2003 / 11$ \\
\hline & & & Loanto & Nuremberg & $2012 / 08$ \\
\hline
\end{tabular}

Table2. Periods of observation

\begin{tabular}{|c|c|c|}
\hline Period & Status & Hours of observation \\
\hline December 2011 & Pilotsudy & 12 \\
\hline January 2012 & Pilotstudy & 17 \\
\hline February 2012 & Pilotstudy & 16 \\
\hline March 2012 & Data collection & 55 \\
\hline April 2012 & Data collection & 70 \\
\hline May 2012 & Data collection & 40 \\
\hline June 2012 & Data collection & 50 \\
\hline
\end{tabular}

\subsection{Recording Conditions}

The manatee pool (see Figure 1) is part of the newly constructed lagoon area at Nuremberg Zoo, finished in August 2011. It consists of the dolphinarium, large outdoor pools for bottlenose dolphins and California sea lions and the Amazonian building, a tropical rain forest building, a walk-through situation for a typical Amazonian lowland forest.

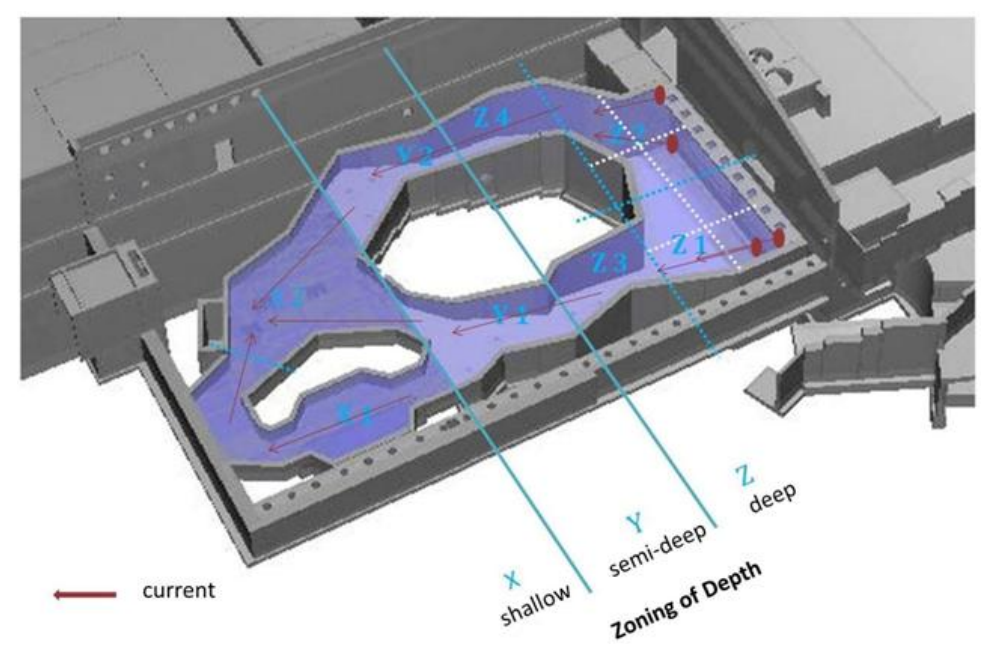

Figure1. Map of the manatee tank with current and spatial zones (edited (C) Nuremberg Zoo 2012)

The manatee pool, an indoor pool, has a maximum length of 32.5 meters and a maximum width of 22.5 meters. The whole area of the Amazonian building covers about 700 square meters, approximately 350 of which are water. The manatee pool, which is filled by fresh water, has a temperature of about 26 degrees Celsius and contains about 700 cubic meters of water.

In addition to the manatees, several species of fish, reptiles and birds are also living in the pool. These are tambaquis (Colossomamacropomum), pearl cichlids (Geophagusbrasiliensis), Doradidae (Pseudodorasniger), Loricariidae (Pterygoplichthysgibbiceps), yellow-spotted river turtles (Podocnemisunifilis) and ringed teals (Callonettaleucophrys). 
The total area of the tank is freely accessible to the manatees 24 hours per day. The tank consists of an O-ring formed main pool, which allows the animals to swim large circles of about 14 meters radius. An adjacent smaller pool can be separated if necessary, e.g. for medical treatments of individual animals. Ecological features of the manatee tanks were mapped according to several criteria.

\subsection{Depth Zoning}

The shallow-water zone (marked byX) with a medium depth of one adult manatee diameter and a maximum depth smaller than the diameter of two manatees' set upon each other.

The transitional-water zoneor semi deep water (marked by Y) with a minimum depth of more than two manatee diameters on top of each other, so that two manatees can easily pass above or below each other without touching, maximum depth smaller than the maximum body length of a manatee, so that no manatee can stand vertically in the area.

The deep-water zone(marked by $\mathrm{Z}$ ) with a minimum depth more than one manatee length such that any adult manatee can be positioned vertically in the water, e.g. for diving or bottom feeding.

\subsection{Visibility}

Most parts of the deep-water area (marked by Z1, Z2, Z3) are easily visible from huge window panes in the dome called "Blauer Salon" an underwater viewing area for visitors. The rest of the tank can be observed from above and inside the Amazonian building (X1, X2, Y1, Y2, Z4). Some parts of the water surface are inconstantly covered by shadows, trees, shrubberies, platforms and other constructional elements.

\subsection{Current}

The tank is served by four direction valves. These are located in the deepest area of the pool, exactly next to the inside of the window panes opening into the "Blauer Salon". The current is running around the islands in the middle of the tank, which is also part of the visitor track in the Amazonian building. Finally, the water runs through a waste water sluice on the opposite end of the tank (see Figure 1). There the water is led to a rotational filter, which removes larger particles (maximum of $420 \mathrm{~m} 3 / \mathrm{h}$, wire mesh diameter $0.07 \mathrm{~mm}$ ). All excreta and small soiled material is swallowed and digested by the fishes in the tank. Due to the closed water system, the consumption of water is being reduced to a minimum. However, the quality of the water is checked on a regular basis.

\subsection{Observational Methodology}

Systematic observations were made in total for 215 hours from March to June 2012, by means of scan sampling in a 10-minutes scan interval, which led to 1126 scans per individual (Altmann, 1974).

During this scan sampling, location and activity of each individual were recorded.

In addition, focal animal sampling, with interval lengths of 10 minutes, was performed on all individuals in order to measure the respiratory frequency. A total of 620 samples were collected (see table 3).

Table3. Data of respiratory frequencies collected by focal animal sampling

\begin{tabular}{|l|l|l|l|l|}
\hline Divingphase [min] & HERBERT & MARA & ZORRO & LUNA \\
\hline Minimum & 0,021 & 0,3 & 0,25 & 1,483 \\
\hline Q25 & 1,633 & 3,038 & 2,529 & 2,267 \\
\hline Median & 2,65 & 4,342 & 3,317 & 3,033 \\
\hline Q75 & 4,233 & 5,696 & 4,25 & 4,842 \\
\hline Maximum & 8,733 & 12,133 & 11,533 & 5,967 \\
\hline Sample size [n] & 207 & 178 & 212 & 23 \\
\hline
\end{tabular}

\subsection{Statistical Analysis}

Statistical analysis was performed by means of $\mathrm{R}$ ( $\mathrm{R}$ Development Core Team), graphics and diagrams were constructed by $\mathrm{R}$ and Excel (Microsoft Corporation).

A spread of participation index, SPI (Plowman, 2003), was calculated for each individual separately and again for the group as a whole, in order to compare both individual preferences and changes in difference over 24 hours.A Kruskal-Wallis-test was performed to compare data of the respiratory frequencies (diving phases) to test for individual differences. The level of significance was set at $=0.05$ (two-tailed). 


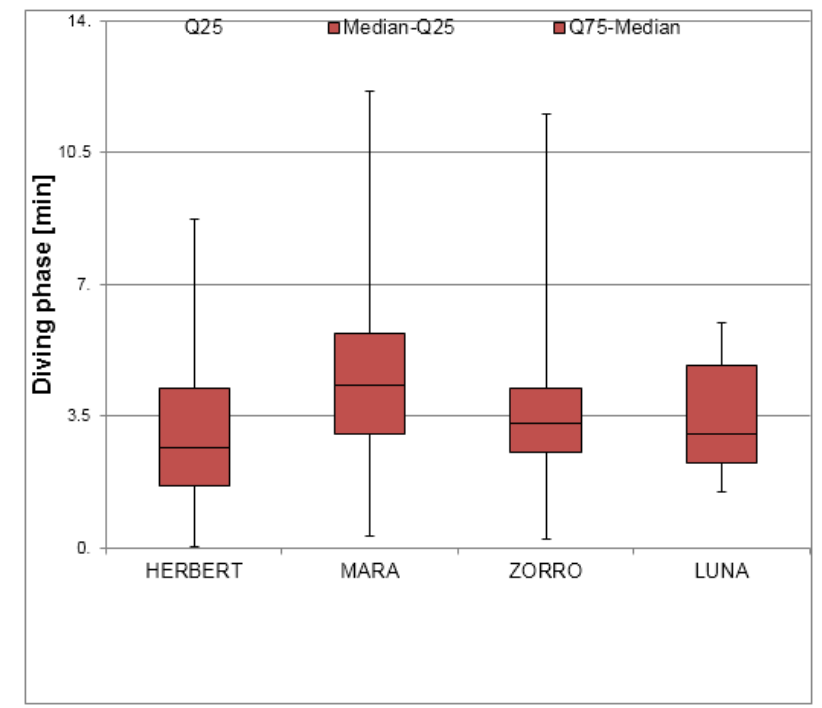

Figure2. Distribution of respiratory frequencies (diving phases) for each manatee

\section{RESULTS}

\subsection{Breathing Frequency}

Table 3 shows the median duration of the diving phases per animal. It can be seen that we found significant differences between the four animals (Kruskal-Wallis chi-squared $=20.449$, df $=3$, pvalue $=0.000137)$. MARA, the large female, has a slightly higher median duration and also her $90 \%$ whisker is slightly longer than the ones of the other individuals. Quite interestingly, LUNA, the newly added female, has quite short median durations as her $90 \%$ whisker is very short compared to the other three animals, even the young male HERBERT.

Unfortunately, no measurements of respiratory frequencies could be taken during the night due to the low level of illumination.

Figure 3 describes the enclosure parts which are specifically frequented during breathing. It can be seen, that all four animals prefer to surface in the deep-water areas (Z1-4) for breathing. Slight differences between HERBERT, MARA and ZORRO exist, LUNA has been added to the group rather shortly during the observation time. Her values thus might not be really representative of her preferential tendencies already. However, taken together, it can be seen that breathing is distributed mostly in the areas next to the window pane and only rarely occurs in the shallow water zones of sections 11 through.

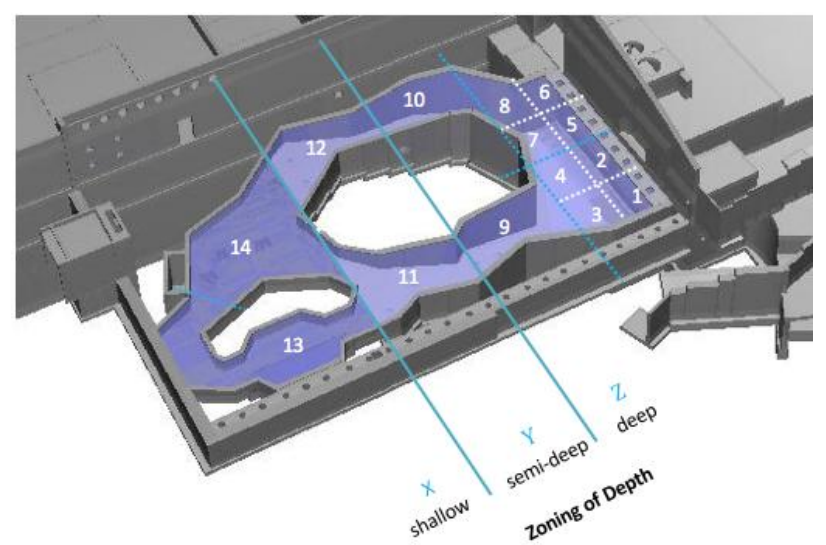

Figure3. Map of the manatee tank divided into grid squares, each filled with similar volume of water; $1-10$ deep-water zone (Z); 11/12 semi-deep-water zone $(Y)$; 13/14 shallow-water zone $(X)$

\subsection{Space Use}

Figure 3 shows the distribution of scan observations for all four animals over all sections of the pool. It can be seen, that the areas Z1 through Z3 are preferred by almost all animals, and the SPI calculated for the whole group has a value of 0,548 . 
As slight differences between the individuals has been noticed from figure 3, the SPI was again recalculated for each individual separately. In that case, HERBERT reaches an SPI of 0,567, MARA reaches 0,549, ZORRO reaches 0,516 and LUNA the newly introduced female 0,842 .

LUNA specifically almost always used the sectors Z1 and Z3 which are the deep-water sections directly in front of the window pane.

\section{DISCUSSION}

The results of the study provide quantified data on breathing patterns and the space-time-structure of the Manatee group and also provide a study design that could potentially be used in a variety of study areas in other zoos and the wild. The observations were made from the visitor area, and data collection, thus, might have been compromised slightly by the observer being part of the visitors, whose influence was also part of the study design. Thus, influences by the observer are comparable to influences of other visitors during daytime, when the manatee area is open both for the underwater viewing and for visitors of the Amazonian building. The situation at night might be different, when the animals are not used to the presence of people. Also, the selection of surfacing areas to breathe might be different during the day light hours.

Visibility generally was rather good. The animals were out of sight only during those times when they swam into the shallow water parts and observation from the window pane was no longer possible. It can be seen from the diagrams figure $\mathrm{x}+2$ that "out of sight"is a neglectable part of the total scan points.

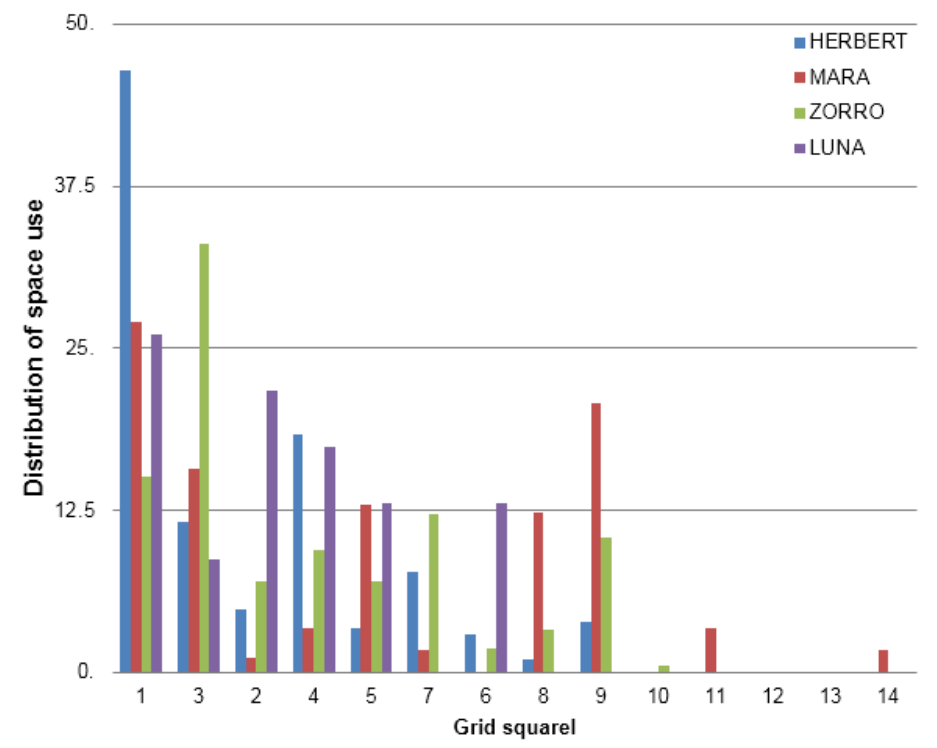

Figure4. Space use data of the manatee individuals linked to the referring numbers on the map; 1 - 10 deepwater zone $(Z)$; 11/12 semi-deep-water zone $(Y)$; 13/14 shallow-water zone $(X)$

Due to the pool being rather diverse by structure and the only parts without specific under water structure are those next to the window pane, the errors in allocating the individuals into the correct sectors are likely to be few.

Regarding previous studies and the data of the breathing frequencies, it can be seen that these (as expressed in median duration of diving phases) seem to depend on body mass and lung volume. Mara, the largest individual, has the longest median duration and the longest $90 \%$ whisker. Luna, the smaller female, had been introduced into the tank only recently, thus, her values might not be representative for her general physiological needs (Mason 2010).

As a whole, there were no long term increases in breathing frequencies per individual compared to individual median. This is contrary to data from bottlenose dolphins, which increase breathing frequency quite considerably during acoustic stress periods (e.g. by boat traffic) (Hastie 2003).

Either the manatees in Nuremberg Zoo do not have any significant stressors in their environment, which might explain why the shortest breathing intervals, as depicted by the $10 \%$ whisker, are rather near the median, as well as the $25 \%$ quartile. Or alternatively breathing frequencies in manatee, contrary to Cetacean data, is less dependent on environmental stressors. 
During the observation time the median per period of the day stayed rather constant which again seems to negate the presence of acute stressors (for example construction noise). The animals seem to be relaxed in using the pond and increased frequencies in breathing (which might refer to activity) do not last for longer periods of time (Borell 2001, Fair 2000, Keeling 2009, Moberg 2000).

The individuals seem to use the pool slightly differently, which can be seen by the different values for the SPI per individual. The males (and LUNA, who however had been introduced into the group recently) tend to use the sectors in a more clumped version than MARA, who distributed her space use more evenly.

During the day, the deep-water areas are preferentially used over the shallow areas, which might be a consequence of visitor noise from above, by people visiting the Amazonian building. Field studies describe differential migratory foraging patterns for different individuals, also locomotor play, courtship and mating behaviour are distributed over different depth zones in the wild. The diverse pattern of space use in our study stresses the importance of heterogeneously structured pools with different zones regarding to depth, breadth and other physical patterns (Arraut 2010, CastelblancoMartínez2009, Shepard 2006).

Manatees in the wild seem to be arrhythmic (Hartman 1979). An influence of daylight on the enclosure use thus might be neglectable. The pattern of space use, when the semi-deep areas are preferentially used during the night, the deep-water zones preferentially during the day, might again point to disturbances by visitor noise during those times that the Amazonian building is open to the public. During the night, the manatees use all available sectors in more evenly distributed patterns.

Taken together data from this preliminary study seem to confirm that size and structuring of the pool are adequate for keeping and breeding manatees in the Nuremberg manatee building.

The results also stress the importance of depth zoning and other physical factors in constructing suitable manatee tanks. Visitor viewing from behind large window pane, as in the "Blauer Salon" in Nuremberg, does not seem to have strong influence on the behaviour of manatees. Care should be taken when visitor viewing from above in shallow water areas is possible, in this case the necessity to also provide access to deep-water zones further away from the visitors, seems to be quite important.

\section{ACKNOWLEDGEMENT}

The authors would like to express their thanks to the director and the staff of the Nuremberg Zoo for the opportunity to work with their animals and the support during this project. We also would like to thank Dr. Lorenzo von Fersen, who continuously provided his expertise that greatly assisted the research.

\section{REFERENCES}

[1] AltmannJ. (1974) ObservationalStudyofBehavior: SamplingMethods. Behaviour 49: 227-267.

[2] ArrautE.M.etal.(2010) The lesser of two evils: season almigrations of Amazonian manatees in the Western Amazon. Journal of Zoology 280: 247-256.

[3] Borell E.H. (2001) The biology of stress and its application to livestock housing and transportation assessment. American Society of Animal Science 79: 260-267.

[4] Castelblanco Martínez D.N. etal. (2009): Seasonality of habitat use, mortality and reproduction of the Vulnerable A ntilleanmanatee Trichechusmanatusmanatus in the Orinoco River, Colombia: Implications for conservation.Oryx 43: 235-242.

[5] Fair P.A. et al. (2000) Review of Stress in Marine Mammals. Journal of Aquatic Ecosystem Stress and Recovery 7: 335-354.

[6] HartmanD.S. (1979) Ecology and Behavior of the Manatee (Trichechusmanatus) in Florida. Dissertation. Department of Conservation,CornellUniversity(ed.Ithaca,NewYork:TheAmericanSocietyof Mammalogists.

[7] Hastie G. (2003) Bottlenose Dolphins Increase Breathing Synchrony in Response to Boat Traffic. Marine Mammal Science 19: 74-84.

[8] Keeling L. et al. (2009) AbnormalBehaviour, Stressand Welfare. In The Ethology of DomesticAnimals. Washington: CABInternational: 85-101.

[9] Marsh H. et al. (2011) Ecology and Conservation of the Sirenia: Dugongs and Manatees. Cambridge University Press, Cambridge, United Kingdom, 536 pp. 
Analysis of Behavioural Patterns of the Amazonian Manatee, Trichechus manatus manatus, under Human Care (Mammalia:Sirenia)

[10] MasonG.J. (2010) SpeciesDifferencesinResponsestoCaptivity: Stress, WelfareandtheComparativeMethod. TrendsinEcology\&Evolution 25: 713-21.

[11] Moberg G.P. et al. (2000) The Biology of Animal Stress: Basic Principles and Implications for Animal Welfare, Wallingford: CAB International.

[12] Plowman A.B. (2003) A note on a modification of the spread of participation index allowing for unequal zones. Applied Animal Behaviour Science 83: 331-336.

[13] Sheppard J.K. et al. (2010) Dugong Habitat Use in Relation to Seagrass Nutrients, Tides, and Diel Cycles. Marine Mammal Science 26: 855-879.

[14] Sheppard J.K. et al (2006) Movement Heterogeneity of Dugongs, Dugong dugon, over large Spatial Scales. Journal of Experimental Marine Biology and Ecology 334: 64-83.

[15] von Fersen L. (2012) Plan Amazonian Building, unreleased Material. Nuremberg: Zoo Nuremberg

[16] von Fersen L. (2011) European Studbook for the ANTILLEAN MANATEE (Trichechusmanatusmanatus) 2. ed., Nuremberg: Zoo Nuremberg.

[17] Wright A.J. et al. (2007) Do Marine Mammals Experience Stress Related to Anthropogenic Noise? International Journal of Comparative Psychology 20: 274-316.

Citation: Kappel Isabelle \& Gansloßer Udo," Analysis of Behavioural Patterns of the Amazonian Manatee, Trichechus manatus manatus, under Human Care (Mammalia:Sirenia)", International Journal of Research Studies in Zoology, vol. 5, no. 4, p. 1-7, 2019. DOI: http://dx.doi.org/10.20431/2454-941X.050401.

Copyright: (c) 2019 Authors. This is an open-access article distributed under the terms of the Creative Commons Attribution License, which permits unrestricted use, distribution, and reproduction in any medium, provided the original author and source are credited. 